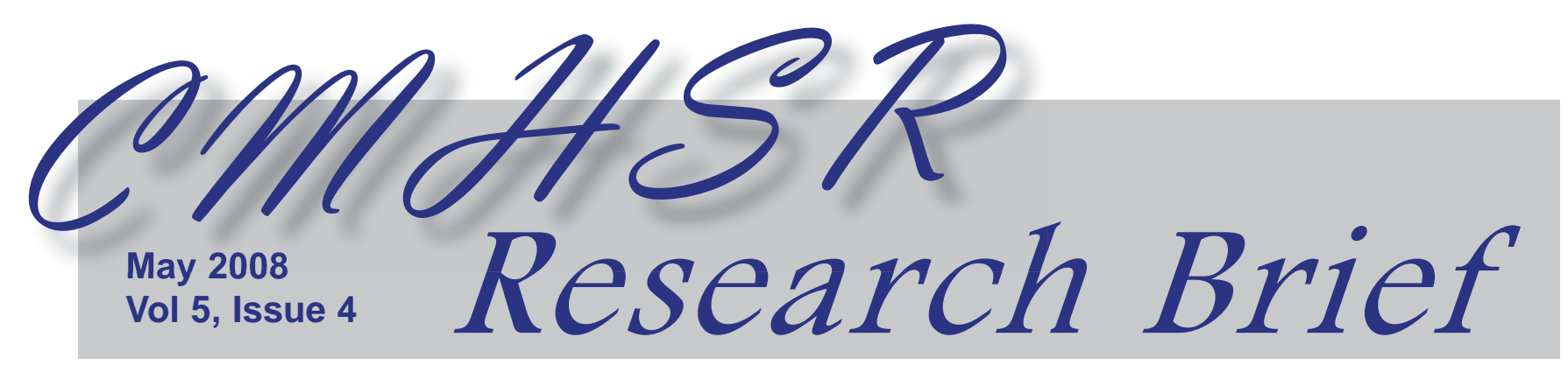

\title{
Community Reintegration of Persons with SMI Post Incarceration
}

Stephanie Hartwell, PhD

I ndividuals diagnosed with severe mental illness (SMI) are disproportionately represented in the criminal justice system. Anywhere from a quarter to nearly half of all individuals with SMI become involved with the criminal justice system over their lives and prisons house three times as many individuals with SMI as hospitals. ${ }^{1}$ Reentry post incarceration is difficult for all ex-inmates, but poses extreme challenges for individuals with SMI. Two-thirds of SMI ex-inmates are rearrested and half are hospitalized within 18 months of release. ${ }^{2}$ Thus without specialized services, programs, or supports, individuals released from correctional custody with SMI fare poorly. ${ }^{3}$ This issue brief provides an overview of specialized services and programs that support exinmates with SMI returning to the community post release with particular attention given to the Massachusetts' Forensic Transition Team (FTT) model.

\section{SMI and the Criminal Justice System}

An increase of individuals with SMI in the criminal justice system resulted from a myriad of forces including deinstitutionalization of state mental hospitals and the Community Mental Health Center Act of 1963.4 Current trends working against comprehensive community based mental health services include declining reimbursements for psychiatric services due to managed care, limited spending on mental health units associated with hospitals, and lack of coercive treatment methodologies in the community. ${ }^{5}$ Persons with SMI who, in the past, were located in institutional settings now struggle for resources in the community where they are at risk for becoming both perpetrators of crime and its victims. 6 At the

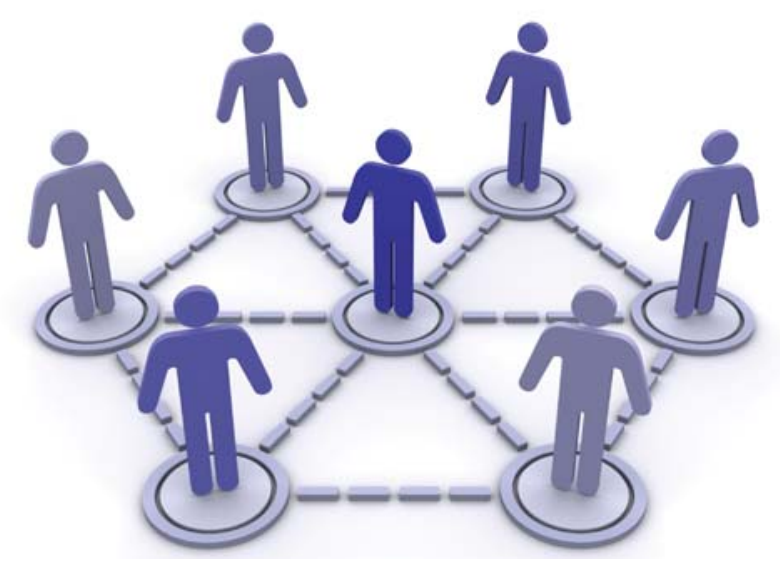

same time, "tough on crime" criminal justice policies, including mandatory sentencing and three strikes laws have resulted in longer terms of incarceration. The result of these systemic and policy changes is the presence of more individuals with SMI in the community, coming into contact with law enforcement, and subsequently becoming involved with the criminal justice system.

\section{Programs Across the Nation}

California, Ohio, and Massachusetts are states with widespread reentry programming for individuals with SMI. In California, funds were legislated to develop multidisciplinary case management and Assertive Community Treatment (ACT) teams for individuals with SMI exiting correctional settings. A meta analysis of the programs through 2004 based bi-annual data collection and case/control designs found cost savings and decreased criminal justice involvement overall. In particular, the group receiving "enhanced services" (ACT, multidisciplinary case management, or mental health court) had fewer bookings, convictions, jail days, problems with drugs/alcohol and more economic self sufficiency.7 In Ohio, a class action suit resulted 
in a consent decree to offer services for individuals with SMI post release from correctional custody across the state. These services range from improved discharge planning to community justice partnerships to address individuals with mental health and substance abuse problems including both the Serious Violent Offender Re-entry Initiative and the Urban Institute's Returning Home Study.8,9 Ohio also developed Forensic Assertive Community Treatment (FACT) teams in 2 of its 88 counties. These teams function like ACT teams for individuals involved with the criminal justice system with a psychiatrist, psychiatric nurse, case managers and a parole officer. ACT teams are effective in helping clients released from hospitals maintain housing and reduce the number of days in the hospital.10 FACT teams seem a promising approach, yet there is limited and relatively mixed data available on their efficacy. ${ }^{11}$

Other smaller, specialized case management programs include the Thresholds Jail Program in Chicago, Illinois. Evaluation of this specialized case management program found that all 24 clients, the vast majority with a history of substance abuse and homelessness, received benefits at release and continued mental health treatment two years after release. The result of the program was a reduction in hospitalizations and jail days and cost savings for the county and state. ${ }^{12}$ The Thresholds program provided the framework for Illinois' Prison Aftercare Program (PAP). ${ }^{13}$ PAP is operated out of two correctional facilities and offers ACT services to releases who meet program criterion including being non-violent. PAP clients receive an array of support services including the completion of benefit applications, scheduling or community appointments, vocational training, and medication maintenance management. Clients continue to be PAP clients after they are rearrested, hospitalized or re-incarcerated. While intensive
ACT-like services post release from correctional custody have some precedent in reducing hospital and jail days with cost savings to public safety in particular, no outcome data are available on the PAP program. ${ }^{14,15}$

Recently, Wilson and Draine ${ }^{16}$ surveyed each state and compiled 50 reentry program descriptions comprised of collaborations between criminal justice and mental health systems. They found that few states have comprehensive statewide transition programs supported by community mental health dollars. The vast majority of services are funded by the criminal justice system. Limited methodologies including lack of comparison groups, standardized followup procedures and data collection methods, and contextual descriptions makes articulating program efficacy in variant contexts via outcome studies nebulous. They conclude that the emphasis on criminal justice and public safety funding streams "isolates" individuals with SMI in the criminal justice system rather than integrating them into the communitybased mental health service system. ${ }^{16}$

\section{Massachusetts' Forensic Transition Team}

In Massachusetts, the statewide Forensic Transition Team (FTT) program mission is to address the needs of offenders with SMI leaving correctional settings. Funded and staffed by Department of Mental Health (DMH) transition coordinators with expertise in prison and community corrections, the FTT's only criterion is that individuals meet a threshold level of major mental illness to receive transition services. An inmate's criminal history does not disqualify him or her from participating in the program. The FTT provides comprehensive transition planning services such as reestablishing entitlement benefits and community service linkages for juvenile and adult SMI offenders incarcerated in state and county correctional

Figure 1. Current Most Serious Governing Offense for FTT Client Sample

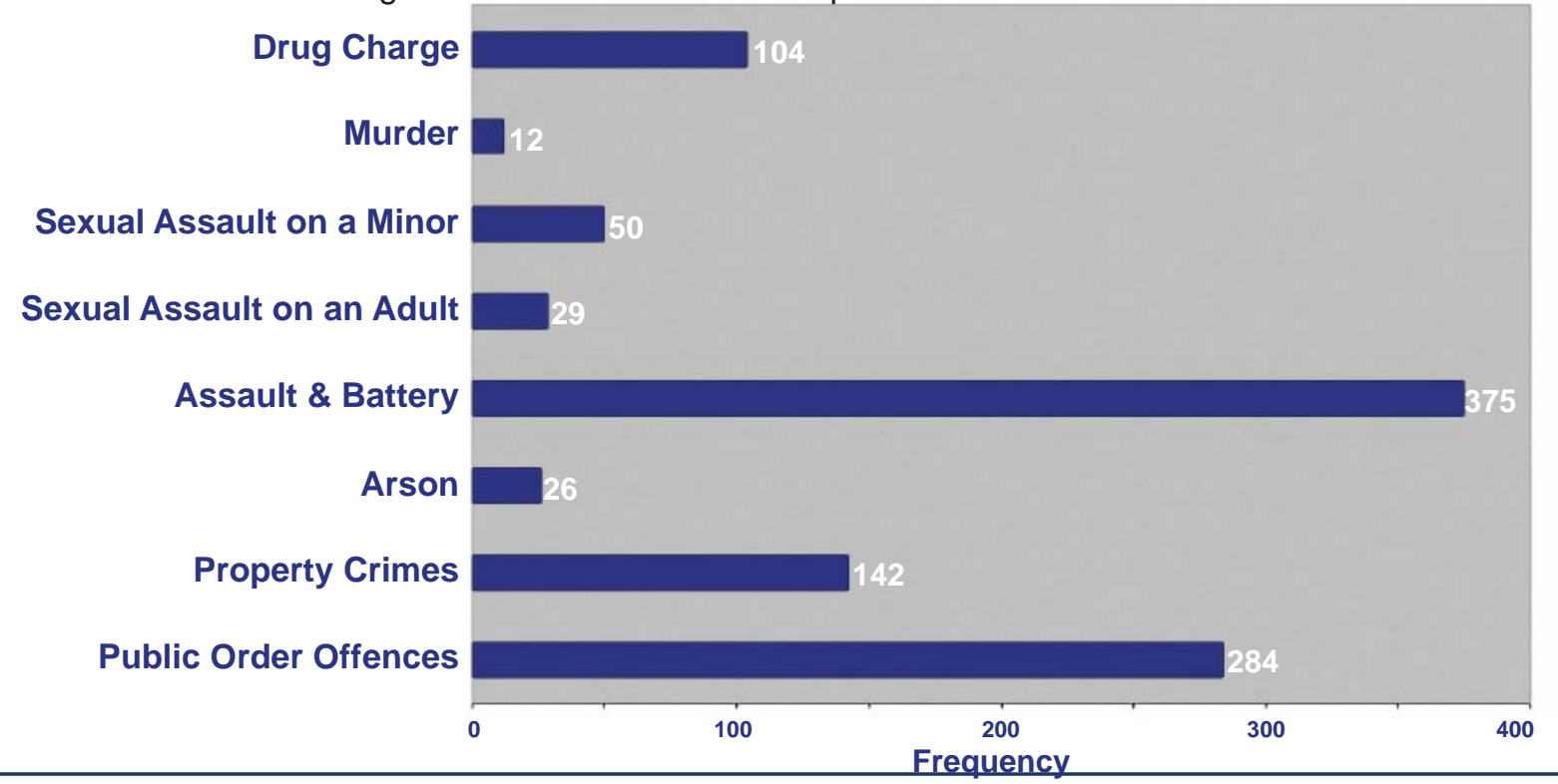


Table 2. Race/Ethnicity by Primary Clinical Symptom**

\begin{tabular}{|c|c|c|c|c|}
\hline Race/Ethnicity & $\begin{array}{c}\text { Thought Disorder } \\
n=492(53 \%)\end{array}$ & $\begin{array}{l}\text { Mood Disorder } \\
n=378(41 \%)\end{array}$ & $\begin{array}{l}\text { Personality Disorder } \\
\qquad n=43(5 \%)\end{array}$ & $\begin{array}{l}\text { Other Primary Disorder } \\
\qquad n=21(2 \%)\end{array}$ \\
\hline \multicolumn{5}{|l|}{ Caucasian } \\
\hline$n=495(53 \%)$ & $222(45 \%)$ & $240(49 \%)$ & $25(5 \%)$ & $8(1 \%)$ \\
\hline \multicolumn{5}{|l|}{ Black } \\
\hline$n=200(21 \%)$ & $142(71 \%)$ & $48(24 \%)$ & $5(3 \%)$ & $5(3 \%)$ \\
\hline \multicolumn{5}{|l|}{ Hispanic } \\
\hline$n=132(14 \%)$ & $44(56 \%)$ & $52(39 \%)$ & $3(2 \%)$ & $3(2 \%)$ \\
\hline \multicolumn{5}{|l|}{ Other } \\
\hline$n=107(12 \%)$ & $54(51 \%)$ & $38(36 \%)$ & $10(9 \%)$ & $5(2 \%)$ \\
\hline \multicolumn{5}{|l|}{$x^{2}=61.49$, d.f. $=8, p<.000$} \\
\hline${ }^{* *}$ Data were missing on $88 \mathrm{c}$ & not equal 100 due & & & \\
\hline
\end{tabular}

institutions. The FTT also works with pre-trial individuals, and individuals who are released under public safety supervision. Distinctive features of the FTT program include that: (1) it is a statewide program, (2) it is funded by $\mathrm{DMH}$, and (3) participation is voluntary. ${ }^{17}$

Hartwell and colleagues have conducted descriptive research on the FTT since the program started in 1998. Figure 1 provides the most serious governing offense for all FTT transition episodes from Houses of Corrections or State Prisons since 1998 ( $n=1,022)$. (See Figure 1). Some findings from this sample have included gender and racial differences. Specifically, females had elevated rates of substance abuse and difficulty with reentry due to their distinct social-cultural roles and being isolated in a single correctional facility in the state. ${ }^{18}$ Additionally, findings highlighted that racial minorities had different clinical profiles (see Table 2) and postrelease outcomes than their non-minority counterparts. ${ }^{19}$

Hartwell and colleagues also conducted an outcome analysis tracking FTT clients for three months post-release from the House of Correction (those with misdemeanor offenses serving sentences averaging 6 to 9 months) and from State Prison (felony offenders serving sentences averaging 4 or more years). On a positive note, the outcome analysis to date suggests that the vast majority of FTT clients are "engaged" in services three months post release as opposed to being rearrested or hospitalized. Table 3 illustrates that FTT clients released from the House of Corrections, those that committed misdemeanor offenses, are at higher risk of being lost from the follow-up and returned to the criminal justice system. While substance abuse and offense history are important variables impacting post release outcomes, Hartwell's most recent research with Fisher suggests regional variation in resources and services has more direct effects on outcomes. ${ }^{20} \mathrm{~A}$ shift to a regionally based model resulted in more client engagement overall 3-months post release, and variations in the outcomes pre and post regionalization remain significantly different when controlling for other variables including length of sentence.

\section{Future Research}

The Urban Institute recently conducted a series of studies on the experiences of ex-inmates released from state correctional facilities. The Institute identified a range of reentry challenges through interviews with inmates pre and post release including substance abuse, limited employment opportunities and entitlements, health problems, and negative attitudes and beliefs about reentry. Ex-inmates also recognized a shortage of supervised release programs and a dearth of financial and/or housing support from families. Finally, they reported environmental variation in resources such as programming, mentoring, and housing that they believed to be essential to reentry. 8,21

Of the four states included in the Urban Institute study, only Ohio, where 1 out of 5 released inmates reported a history of mental health service use, specifically focused on the experience of ex-inmates with health and mental health problems. ${ }^{9}$

In sum, the majority of existing literature on correctional reentry identifies the domains considered vital for community reentry for the general population of offenders. Little standardized knowledge has been accrued on these domains and the experience of released offenders with SMI. Thus, research, similar in scope and method to the Urban Institute study, should be undertaken to understand the experiences of ex-offenders with SMI from point of release. The proliferation of smaller scale research studies described herein, including Hartwell's research with the FTT in Massachusetts provides the backdrop to support larger scale research and the next generation of services research focusing on this population. 
Table 3. Outcomes for FTT Clients By Type of Institution From Which They Were Released $(n=1012)^{\star}$

\begin{tabular}{|l|c|c|c|}
\hline \multicolumn{1}{|c|}{ Outcome } & $\begin{array}{c}\text { Total Sample } \\
(n=1012)\end{array}$ & $\begin{array}{c}\text { House of Correction } \\
(n=564)\end{array}$ & $\begin{array}{c}\text { State Prison } \\
(n=448)\end{array}$ \\
\hline Engaged in Services & & $300(53 \%)$ & $161(36 \%)$ \\
\hline Lost to Follow-up & $135(13 \%)$ & $101(18 \%)$ & $34(8 \%)$ \\
\hline Immediately Hospitalized at Release & $199(20 \%)$ & $37(7 \%)$ & $162(36 \%)$ \\
\hline Re-Hospitalized & $37(4 \%)$ & $17(3 \%)$ & $20(5 \%)$ \\
\hline Re-Incarcerated & $145(14 \%)$ & $83(15 \%)$ & $62(14 \%)$ \\
\hline Re-adjudicated within 3 Months & $35(4 \%)$ & $26(5 \%)$ & $9(2 \%)$ \\
\hline $\begin{array}{l}\text { X2=1.54, d.f.=5, p<.001 } \\
\text { *Post Release Data missing information on ten cases. Percents do not equal 100 due to rounding error. }\end{array}$ & & \\
\hline
\end{tabular}

\section{References}

1. President's New Freedom Commission on Mental Health. (2002). Interim report of the president's new freedom commission on mental health. Washington, DC: Author.

2. Feder, L. (1991). A comparison of the community adjustment of mentally ill offenders with those from the general population. Law and Human Behavior, 15, 477493.

3. Hartwell, S. W. (2003). Short term outcomes for offenders with mental illness released from incarceration. International Journal of Offender Therapy and Comparative Criminology, 47(2), 145-158.

4. Hiday, V.A.. 1999. Mental illness in the criminal justice system. In A.V. Horwitz \& TJ.L. Scheid (Eds.), $A$ handbook for the study of mental health social contexts, theories, and systems, Cambridge University Press, or Fisher, W. H, (Ed), (2003). Community based interventions for criminal offenders with severe mental illness. New York, NY: Elsevier.

5. Appelbaum, P. (2002). Starving in the midst of plenty: The mental health care crisis in America. Psychiatric Services, 53, 1247-1252.

6. Teplin, L. A., McClelland, G., Abram, K. M., \& Weiner, D. (2005). Crime victimization in adults with severe mental illness: Comparison with the national crime victimization survey. Archives of General Psychiatry, 62, 911921

7. Spaite, P. W., \& Davis, M. S. (2005). The mentally ill and the criminal justice system: A review of programs. Columbus: National alliance on mental illness. http:// namiohio.org/REVIEW_PROGRAMS.pdf.

8. Travis, J. (2005). But they all come back: Facing the challenges of prisoner reentry. Washington, DC: Urban Institute Press

9. Visher, C., Baer, D., \& Naser, R. (2006). Ohio prisoners' reflections on returning home. Washington, DC: The Urban Institute.

10. Mueser, K., Bond, G. R., Drake, R. E. \& Resnick, S. G. (1998). Models of community care for severe mental illness: A review of the research on case management. Schizophrenia Bulletin, 24, 37-74.
11. Morrissey, J. \& Meyer, P. (2005). Extending assertive community treatment to criminal justice settings. The National GAINS Center for Systemic Change for Justice-Involved People with Mental Illness.

12. McCoy, M. L., Roberts, D. L., Hanrahan, P., Clay, R., \& Luchins, D. J. (2004). Jail linkage assertive community treatment services for individuals with mental illness. Psychiatric Rehabilitation Journal, 27, 243-250.

13. Lurigio, A.J., Rollins, A., \& Fallon, J. (2004). The effects of serious mental illness on offender reentry. Federal Probation. 68,2. http://www.uscourts.gov/fedprob/September_2004/illness.html

14. Lurigio, A. J., \& Swartz, J. A. (2002). Changing the contours of the criminal justice system to meet the needs of persons with serious mental illness. In J. Horney (Ed.), Policies, processes, and decisions of the criminal justice system (pp. 45-108). Washington DC: U.S. Department of Justice, National Institute of Justice.

15. Lurigio, A. J., \& Lewis, D. A. (1987). The Criminal mental patient: A descriptive analysis and suggestions for future research. Criminal Justice and Behavior, 14, 268-287.

16. Wilson, A. B., \& Draine, J. (2006). Collaborations between criminal justice and mental health systems for prisoner reentry. Psychiatric Services, 57, 875-878.

17. Hartwell, S. W., \& Orr K. (1999). The Massachusetts forensic transition team for mentally ill offenders reentering the community. Psychiatric Services, 50, 12201222.

18. Hartwell, S. W. (2001). Female mentally ill offenders and their community reintegration needs: An initial examination. International Journal of Law and Psychiatry, 24, 1-11.

19. Hartwell, S. W. (2001). An examination of racial differences among mentally ill offenders in Massachusetts. Psychiatric Services, 52, 234-237

20. Hartwell, S. W. \& Fisher, W. H. (Under Review). The impact of regionalization on reentry service outcomes.

21. Visher, C. \& Courtney, S. M. E. (2006). Cleveland prisoners' experiences returning home. Washington, DC: The Urban Institute.

Visit us on-line at http://www.umassmed.edu/cmhsr Send Comments to CMHSR@umassmed.edu 